\title{
Iranian L2 Researchers' Perspectives on Research Ethics
}

\author{
Perspectivas de investigadores iraníes de segunda lengua \\ sobre la ética de la investigación
}

\author{
Gharaveisi, Zhila'; \\ Dastgoshadeh, Adel $^{2}$
}

\begin{abstract}
This study aims at exploring L2 researchers' perspectives on research ethics in Iran. A total of ten teacher researchers were selected among a larger group of researchers based on the criteria of academic degree and familiarity with research principles. They were interviewed about different aspects of research ethics. Their responses were audio-recorded and transcribed by the researcher. Finally, the emerging themes were extracted from the responses which showed plagiarism, data management, participant rights, and authorship rights as the most frequent themes discussed by the respondents. Furthermore, the extent of the participants' self-expressed adherence to ethical considerations in research was differential, ranging from a minimum amount of adherence to an acceptable degree of adherence and commitment to research ethics. In addition, the results showed that not all participants had a clear understanding and definition of the four major themes which emerged from the results.

Keywords: ethical principles, perspectives of ethics, research ethics, themes of ethics.
\end{abstract}

\section{Resumen}

Este estudio tiene como objeto explorar las perspectivas de investigadores de segunda lengua sobre la ética de la investigación en Irán. Un total de diez profesores-investigadores se seleccionaron entre un grupo mayor, con base en los criterios de grado académico y familiaridad con los principios

Zhila Gharaveisi has received her MA in TEFL from Islamic Azad University, Sanandaj Branch, Iran. She has taught English language in different institutes for more than nine years. gharaveisi.zhila@iausdj.ac.ir

Adel Dastgoshadeh is an Assistant Professor at the Department of English, Islamic Azad University, Sanandaj Branch, Iran. He holds a Ph.D in TEFL. He has published and presented a number of articles in different journals and conferences. His areas of interest include discourse analysis, sociolinguistics, and teacher education. adastgoshadeh@iausdj.ac.ir

Received: April 11th, 2019. Accepted: December 13th, 2019

This article is licensed under a Creative Commons Attribution-Non-Commercial-No-Derivatives 4.0 International License. License Deed can be consulted at https://creativecommons.org/licenses/by-ncnd/4.0/ 
Zhila Gharaveisi,

Adel Dastgoshadeh

de la investigación. A los profesores-investigadores se les entrevistó sobre diferentes aspectos de la ética de la investigación. Sus respuestas fueron grabadas y transcritas por el investigador. Finalmente, los temas emergentes se extrajeron de las respuestas de los participantes referentes a plagio, manejo de datos, derechos de los participantes y derechos de autor. Además, la adherencia a las consideraciones éticas de la investigación de los participantes fue diferencial, la cual oscila entre una cantidad mínima y aceptable. De igual manera, los resultados muestran que no todos los participantes tuvieron un claro entendimiento ni una clara definición de los cuatro temas que emergieron de los resultados.

Palabras clave: principios éticos, perspectivas de la ética, ética de la investigación, temas de ética.

\section{Background}

In their book, Second Language Research, Methodology and Design, Mackey and Gass (2005) review the history of ethical considerations in second language research. They present a principled discussion of why adhering to ethics in research involving human subjects is necessary. Ethical issues in research have also been attested across committees and organizations in charge of ethics in social sciences research as the U.S. Department of Health and Human Services (DHHS), the Office of Human Subjects Research (OHSR), the U.S. National Institutes of Health (NIH), the U.S. Office for Human Research Protections (OHRP), and the Institutional Review Boards (IRBs) of various universities, which provide guidelines for writing informed consent documents, for example, Harvard's The Intelligent Scholar's Guide to the Use of Human Subjects in Research (2000) (Mackey \& Gass, 2005).

Despite the great verity in social sciences and humanities research methods, all researchers have to recognize and take into consideration a number of fundamental ethical principles while conducting research tasks or projects which are considered equally applicable to all areas of enquiry. Among such ethical considerations, reference can be made to the documentation of the sources from which a researcher borrows oral and/or written materials including words, phrases, clauses, sentences and beyond. This is because crediting sources is ethically necessary since obtaining others' permission is required when one is quoting their words.

Newman and Ratliff (2001) have compared linguistics with anthropology and sociology and expressed concern about the little awareness that the former gives about ethical considerations. Second language acquisition (SLA) seems to share this orientation with linguistics in general. Such unawareness of ethical matters in the field of SLA has been attributed by Ortega (2005, p. 429) to an "illusion that somehow neutrality is inherent in the concerns of the field".

If ethical issues in SLA research are important and should be taken seriously by SLA researchers while doing research, sufficient attention should be paid to familiarizing L2 researchers with the fundamental principles of ethics and ethicality in conducting L2 research studies. Only then can one expect a healthy atmosphere in which useful and well- 
grounded research studies will be carried out without being muddied with the inconsistencies and inadequacies created by lack of adherence to and compliance with ethics and ethicality.

However, before trying to make L2 researchers familiar with ethical issues in second language research, it is worth exploring their perspectives on ethics in second language research in order to learn their attitudes and perceptions about research ethics and the extent to which they agree on the importance of ethics in conducting L2 research to understand how much they are ethics-oriented. Previous studies on ethical matters in research in Iran have addressed research ethics from such perspectives as plagiarism as an instance of academic dishonesty (Rezanejad \& Rezaei, 2013), the reasons behind plagiarism (Bamford \& Sergiou, 2005), academic cheating (Ahmadi, 2012), and perceptions of plagiarism (Mahdavi-Zafarghandi, Khoshroo, \& Barkat, 2012). However, no study seems to have addressed the researchers' perspectives of ethical issues in second language research in Iran.

Non-ethicality in SLA research can cause problems which certainly obstruct reaching dependable conclusions about the teaching and learning of a second language and consequently, misguide the profession from obtaining reliable findings. Furthermore, undue attention to ethical considerations will undoubtedly cause a lot of harm to the rights of other researchers and scholars in the field as their ownership rights and trustworthiness rights might be violated and ignored. Obviously, many codes of ethics have been proposed and implemented across the world, and L2 researchers in many parts of the world are already familiar with these codes of ethics and have internalized the habit of following them while conducting research. Instances of these codes of ethics can be honest crediting of sources, avoiding plagiarism, observing authorship rights, etc. The important point to be highly taken seriously is to explore the Iranian L2 researchers' perspectives about these ethical issues and the extent to which they are willing and determined to follow them in their research studies. In other words, the problem relates to whether SLA researchers in the Iranian context are familiar with and careful about ethical considerations for conducting research in addition to their specialized and technical knowledge, which is taken for granted as the sole basis for being a researcher in our context.

The significance of ethicality for researchers in all contexts in general, and for those in the Iranian context in particular, relates to the fact that both contexts are highly dependent on the outcomes of research, and such dependence makes sense only if researchers follow those principles which guarantee the reliability of research findings. Ethicality is one of these principles. Therefore, the present study aimed to investigate how L2 (English language) researchers in Iran, within the scope of current study, conceptualize research ethics, and what their perspectives and priorities of ethical issues in research are. 
Zhila Gharaveisi,

Adel Dastgoshadeh

\section{Review of Literature}

As Kelman (2007) observes, the emergence of systematic ethical awareness in the behavioral sciences dates back to as early as the 1960s. Kelman (2007) ponders the ethical considerations as "an integral component of the research process itself, on a par with theoretical and methodological concerns - based on the proposition that what we learn through our research is intimately linked to how we learn it” (p. xiv). Similarly, Kimmel (2007) emphasizes the importance of ethical decision-making in modern research and sketches such issues as notorious cases of ethical misconduct which have either misrepresented research results, caused research participants much harm and inconvenience, and ruined the researchers' reputations, or negatively changed public opinion and tolerance for social sciences research.

Ethics in applied linguistics research. In spite of the differences in the nature, definition, and consequences of ethical issues across different scientific domains including applied linguistics, it is generally agreed that ethics forms an integral ingredient of any piece of research of whatever type and focus. SLA is no exception. Suffice it to say here that Allwright (2005) counts ethical issues as one of the three major considerations of exploratory practice or research when he argues that technical, epistemological, and ethical dimensions of research on second language learning form the three main issues to be considered by L2 researchers. In so doing, Allwright (2005) suggests that the ethical dimension of research is just as important and worthy of attention as are the technical and epistemological dimensions of research, which are normally the subject matter of technical texts on research and research methodology.

Specifically, with reference to SLA research, there seems to be a paucity of literature on ethics, however. Even the works of such leading figures and scholars as Larsen-Freeman and Long (1991), Ellis (1994), Gass and Selinker (2007), and VanPatten and Williams (2007), as prestigious textbooks on SLA methods, lack any reference to ethics, which is really surprising considering the significance of ethics in doing research. SLA seems to be inheriting this tradition from its relative discipline, linguistics, which also lacks any concern with ethical issues compared to anthropology and sociology. Ortega (2005, p. 429) argues that this

110 reluctance to apply ethics in SLA research stems fromto the "illusion that somehow neutrality is inherent in the concerns of the field" and questions this position by arguing that "valuefree research is impossible" (p. 432).

Gottlieb (1997) also rejects the assumption that all research including ESL research is being carried out ethically, transparently, and unproblematically. Rather, he recommends investigating the beliefs and practices of ESL researchers to find out what ethical issues are involved. 
Researchers' perspectives on research ethics inside Iran. Perspectives, perceptions, and conceptualizations about ethical issues in research as well as degrees of adherence to research ethics may vary from individual to individual and culture to culture. Consequently, it is worth discussing the perceptions of research ethics and amount of adherence and dedication to ethical issues inside the Iranian setting. Regarding the differences in views about research ethics and adherence to ethical considerations in research, Aba-Sha'ar (2017) comments that, "Research ethics is an important part of [the] professional life of every researcher and it influences society in multiple ways. However, perception of ethics, its principles and its importance may significantly vary between individuals, disciplines, and countries" (p. 2).

Mahdavi-Zafarghandi, et al. (2012) investigated Iranian EFL masters students' perceptions and understanding of the concept of plagiarism, their perceived seriousness of plagiarism, and the rates of the prevalence of different forms of plagiarism. Through a survey study using a questionnaire, they found that plagiarism was a common phenomenon among the students and that they had an inadequate conceptualization of different forms of plagiarism. They also found that "prevalence rates of plagiarism were negatively correlated with both perceived seriousness and understanding of plagiarism at significant levels. Third, perceived seriousness of plagiarism was a predictor of prevalence rates of plagiarism among Iranian EFL Masters students" (p. 69). The authors did not observe any significant relationship between the participants' understanding of plagiarism and their years of study, which they interpreted as suggesting that they were experiencing serious challenges with accurately recognizing the different forms of plagiarism in their academic lives.

Rezanejad and Rezaei (2013) examined Iranian EFL learners' perceptions and familiarity with plagiarism, their attitudes toward their professors with respect to plagiarism, and their proposed justification and reasons for committing plagiarism. The subjects of the study were 122 undergraduate and graduate EFL students of English literature, linguistics, translation, and TEFL. They responded to a questionnaire measuring these constructs which had been piloted and validated by the researchers. The results of their study revealed that the students had different conceptualizations and perceptions of plagiarism, and that plagiarism was mostly considered by them as the use of someone else's words as one's own, but they did not consider it to mean taking someone's ideas without permission. The authors also found that the students considered copying their classmates' and friends' assignments as instances of academic dishonesty in their academic career. According to this study, the students believed that their instructors and professors only made guesses and suppositions about their students having committed plagiarism rather than actually checking and controlling the submitted assignments to find out who has really plagiarized. The results also showed that Iranian EFL learners had different reasons and justifications for plagiarizing, the most important one of which was the ease of doing their assignments through plagiarism. Finally, 
Zhila Gharaveisi,

Adel Dastgoshadeh

the study indicated that the majority of the subjects had been made familiar with the concept of plagiarism and the different forms of its realization by their professors at university.

Due to the scarcity of studies exploring the perspectives held by Iranian L2 researchers about research ethics, and the need for elaborating and explicating such perspectives in an attempt to provide a more comprehensive view of these perspectives, the present study has aimed at further investigating Iranian L2 researchers' perspectives on ethical considerations in conducting research. Inspired by the above general aim, this study has specifically aimed at providing the answers to the following research questions:

RQ1: What are the Iranian L2 researchers' perspectives on ethics in SLA research?

RQ2: To what extent do Iranian L2 researchers converge on the nature and significance of ethics in $\mathrm{L} 2$ research?

\section{Method}

Research approach and design. It is believed that quantitative studies distinctly situate the researcher on the periphery. Therefore, to get a deeper understanding and a more comprehensive picture of the question under investigation, some researchers prefer to conduct contextually sensitive case studies through which they can come up with a more profound understanding and awareness of the different angles of the problem being addressed (Hoy, 2008; Seferoğlu, Korkmazgil, \& Ölçü, 2009). This view of research is in line with the definition of qualitative research as "any kind of research that produces findings not arrived at by means of statistical procedures or other means of quantification" (Strauss \& Corbin, 1990, p. 17). Because of this, qualitative methods of research are more appropriate in situations in which quantitative measures cannot adequately describe or interpret the issue being investigated (Hoepfl, 1997) and - as in this specific case - where the research questions are open-ended e.g. 'what', 'how', or 'why' questions. Qualitative research studies have also been claimed to have the "ability of elucidating situations that are otherwise enigmatic or confusing” (Hiver, 2010, p. 25). This study is descriptive in nature and follows a qualitative design.

112 Research sample. This study used criterion sampling as participants all met some "specific predetermined criteria" (Dörnyei, 2007, p.128). Initial selection of participants for this study was from a cohort of private institute and public school English teachers in Sanandaj and some other neighboring cities in the Kurdistan Province, where they were teaching English. Those living in Sanandaj were invited to participate in a session held in a conference hall where the researcher elaborated on the nature, purpose, and implementation of the research project. Those living out of Sanandaj were provided with a detailed descriptive statement explaining the same details about the research project plus a letter of invitation, 
delivered to the relevant school principals who were asked to inform their fellow teachers about the statement.

Also, the criteria for participating in the study were explained to the participants. A total of 15 teacher researchers from those attending the session in person and 7 teacher researchers among those receiving the written statements and invitation letter completed the total of 22 researchers, who considered themselves as enrolled for actual participation and announced their cooperation in the subsequent phases of the study. Then, an initial screening interview was administered from which 15 researchers were selected. They held at least a master's degree in TEFL and had a minimum of 4 research papers published in creditable journals accepted by the Iranian Ministry of Education and the Ministry of Science, Research, and Technology.

These participants were selected for the next phase of the interview. This phase aimed at assessing their familiarity with the principles of research, publication procedures, ethical considerations in conducting research, reviewing processes of journals, statistical analysis and data collection procedures, participants' rights, as well as aim and significance of conducting research. In addition, they were interviewed on the extent to which they used to read published papers in their field of specialization. Finally, as allowed by considerations of practicality, a total of 10 teacher researchers (6 females: 2 Ph.D., 4 M.A. -4 males: 1 Ph.D., 3 M.A.) were selected as the ultimate participants of the study. Below, a brief description of each of the participants will be presented with their own chosen pseudonyms to ensure anonymity.

Instrumentation. The instrument used in this study was a guided interview, following Mehrani (2015), aimed at assessing the participants' perspectives on research ethics. In line with an extensive review of the literature on research ethics, some frequently recurring themes could be extracted as the basis of interview questions; for example, plagiarism, truthfulness in representing research data, authorship in publishing research papers, confidentiality and anonymity, reporting research results, interference, conflict of interest, conscientiousness, accurate citation, and referencing. However, in order to tap into the participants' genuine ideas and perspectives, the interview was designed in an open-ended format to allow for freedom of opinion and a wider scope of data elicitation aimed at identifying the most frequent patterns of responses, then coming up with emergent themes out of those responses. Therefore, the initial draft of the interview consisted of eight questions and was submitted to the judgment of a panel of experts including my research supervisor, who was an experienced interviewer specialized in educational assessment, for further scrutiny until they agreed on the following five open-ended questions:

1. What do you think about research ethics?

2. What ethical considerations do you think are worth paying attention to by L2 researchers? 
Zhila Gharaveisi,

Adel Dastgoshadeh

3. What is the significance of research ethics in conducting L2 research?

4. To what extent do you think L2 researchers in our Iranian context adhere to ethical considerations while conducting research?

5. To what extent do you yourself adhere to ethical considerations while conducting research?

Data elicitation procedure. The guided interviews were conducted in a classroom at one of the schools in Sanandaj and were conducted entirely in English, as the participants were researchers with high levels of proficiency in using English. The interviewees' responses were audio-recorded by an MP3 recorder placed to the side of the interview area within a feasible distance of the interview location. The interviewer began with a brief preliminary warm-up to establish a non-threatening environment and put the interviewees at ease. The subjects, given guarantees of confidentiality and anonymity, were requested to sign the consent form designed for this purpose, and ask any questions they had in mind about this project or their data. Once being 'on-topic', the interviewer requested that the interviewees press the record button themselves feeling free to pause or switch the device off whenever they liked for any possible reason. None of the subjects chose to pause or stop the recording device, but this option was introduced to further minimize any stress, gap, or distance between the interviewer and the interviewee. It took almost 30 minutes to administer each interview, including the warm-up phase.

Data analysis. After administering the interviews, the researcher transcribed the audiorecorded scripts using a traditional listen-pause-type method, following Hiver (2010). Each audio script produced almost 4 to 5 pages of single-spaced written transcription data. As the content of the interview was of interest to the researcher, it was decided to edit out slight speech imperfections and other surface phenomena to concentrate on the actual words of the interviewees. As the researcher was seeking to extract the most frequently-recurring perspectives and themes out of the transcribed data, she devised a coding scheme to code the data. To ensure the reliability of the rating, she asked a colleague for "peer checking" (Dörnyei, 2007, p. 61). To this end, a briefing session was scheduled to discuss the coding categories and settle any possible inconsistencies in the coding. Then, the colleague performed a coding reliability test by coding two randomly selected passages from each participant's interview transcript. To check the inter-rater reliability of the coding, the correlation between the two raters' codes was calculated which showed a high index of reliability, that is, .87 .

\section{Findings}

Definition and significance of research ethics from the participants' perspective. As regards the first and third research questions, four of the teacher researchers did not show 
any strong seriousness about how ethics and ethical considerations and their significance should be defined and elaborated upon, as they thought almost nothing of the significance of such matters in conducting scientific research.

What research does bring for us and society is important and not how it is done. We are concerned about findings and outcomes not about ethical points.

This was how one participant defined and thought about the definition and significance of research ethics. S/he was thinking in a radically positivistic (objective) way focusing on the consequences of research not procedures and processes, in some way believing that 'the end justifies the means'.

Here is another participant's response:

If we get confined within the ethical limits, we will never obtain our scientific goals. It is often impossible to make progress while seeking spirituality issues.

The above quote belongs to one of the respondents who believed that ethicality was getting in the way of scientific development. S/he was considering ethicality to be confining and restricting. Still, another participant viewed research ethics as devastating and embarrassing to a successful researcher, as $\mathrm{s} /$ he believed that the tremendous scientific developments in the West were due to their having passed over or skipped such ethical boundaries and limitations.

Let us forget about such good-for-nothing questions as etbics and humanitarian outlook on phenomena. Unless one decides to part with big claims of legality and ethic, they will do no good to the society and people.

Six participants, however, valued research ethics and ethical matters. They viewed ethicality as the most determining factor for doing research, arguing that unless a researcher does everything right, his/her research will do no good to humanity. They held the attitude that, unlike some people's beliefs, lack of progress and development is mainly due to the fact that researchers do not act ethically, that they do not adhere to ethical considerations in conducting research, and that misrepresentations of research findings and research data, which result in destructive consequences, are all due to unethical research procedures.

Research without ethics is scarcely ever called research. It should be named malpractice and wrongdoing. Ethics is defined as the cornerstone of everything including research. Ethics is the goal of even research itself. The significance of ethics is so far as we can claim that even the outcomes of research which are to the benefit of society are for reaching ethical goals by the researcher. To do research is to solve problems of mankind and to solve problems of mankind is to be ethical. Therefore, ethics is the end-product of research, not the means of doing research.

Four others believed something in between, arguing that ethics can be considered neither the final goal of research nor as a trivial matter. On the contrary, they believed that ethics is at least a means to an end. The end refers to the development of human knowledge 
Zhila Gharaveisi,

Adel Dastgoshadeh

and the means is whatever helps achieve this purpose. If ethics is not present in scientific enquiries, they may be destructive rather than constructive because they may be, at the very least, misleading; the results cannot be objective and real without a researcher's adherence to ethical principles of research.

We can say that ethics is neither everything in research and boast about its significance nor totally disregard it. To me, it is defined as honesty and truthfulness in all steps of research, be it from the formulation of a genuine research question, the collection of research data, statistical steps, or to the reporting and interpretation of the research results.

In a similar vein, there were six respondents who held a balanced position about research ethics. They argued that research ethics can be defined in the same way as it is defined in real life practices and behaviors, i.e., following what is morally right. Ethics in research is not a new concept in comparison to ethics in everyday life activities. Ethics forms the basis of every bit of human activities, beliefs, and so forth. Ethics is integrated into every aspect of good practice and behavior. Below is the transcription of one of the participants' responses in this regard.

No one can separate ethics from what s/ he does both in everyday real-life activities and in academic endeavors. Ethics should be the basis of everything by the layman and the scholars in scientific circles. Otherwise, no piece of action will lead to useful results. Ethics is an evidentiary concept which needs no definition even. It is part of our being. It is self-evident. And research is no exception.

The above extracts and the interpretations preceding or following them constitute the main section of the responses relating to research questions 1 and 3. In the following section, a description of the responses in terms of the emerging themes will be presented together with the researcher's own elaboration and explication of the responses. As stated above, the four emergent themes will be presented one by one. Plagiarism is the first of these themes.

The four emerging themes. Along similar lines, a corresponding pattern of responses and perspectives about the four major emerging themes was found similar to the one emerging for research questions 1 and 3. The participants who were indifferent towards ethics in research either made little reference to instances of research ethics or turned out to be reluctant to consider the issues which happened to be the major themes in this study. Below, a pattern of responses with increasing attention to ethical considerations has been provided which shows in a stepwise fashion the degree to which the participants referred to and valued ethical themes. Overall, four major themes were drawn out of the responses, namely, plagiarism, data management and representation, participant rights, and authorship. These have been discussed and interpreted with reference to research questions 2, 4, and 5. The following transcriptions are instances of the participants' responses given during the interviews with the researcher. 
I believe that the major ethical responsibility of a researcher is to find the answer to a research question. If s/ he manages to do this s/ he has done his/her duty completely. What can be more important and useful than solving human problems? What ethical considerations can outweigh such an accomplishment? Therefore, the researcher's main job is to do research and provide people with knowledge. The rest do not seem to be as important. Ethical issues proposed (or found?) in research sources are only theoretical discussions which do not impinge upon and concern the researcher in practice.

Another participant stated:

As I said before, ethical considerations play no role in conducting research. If I am going to talk about any ethical points, it will be the permission to take another person's words, though it would not make much difference whether to be honest in quoting others or not because the most important point is to do research and help the society even if one has reported others' words as one's own. What change will this make in the essence of the research being done? Who cares about morality or immorality in citations and referencing while the goal is to be scientific and knowledgeable? To help people is the matter, not pretending to be ethical and moral. A researcher's role is to provide evidence, to answer questions, to solve problems. Research data can also be collected and interpreted in any way because research subjects rarely ever respond enthusiastically and bonestly. Especially in social sciences research such as SLA research; nobody ever is fixed and careful in his/ her responses. Second language learners are changing moment by moment and show different patterns of language behavior. So how can we obtain reliable linguistic responses? How can we add up all of a researcher's duties to ethical issues while we know that these are all nonsense words that some people say? Personally, I don't think researchers in Iran or other parts of the world stick to ethical regulations for conducting research. Otherwise, they would get little or nothing out of their studies. What does it matter if authorship conventions are or are not followed while the aim is to provide the world with new insights? Being first or second author, of course, matters to the authors, but not to the vast audience benefiting from the findings of the research. Whose interests to be primary in a published paper might be important to the authors but not significant to the whole universe? Seldom do I care about such things in doing my research except some vital ones such as matching discussions to the statistical results. I see no point in recommending fellow researchers to adhere to such ethical rules because I believe that researchers have other more important things to do.

The above quotes indicate radically indifferent orientations towards ethics in conducting research. Those participants, while being involved in doing research and publishing highquality research papers, did not seem to be concerned about the way they get things done and the way they get papers published. The section which follows shows a more appreciative approach to research ethics by another participant.

I think the ethical considerations to care about include the honesty and objectivity of referring to somebody else's phrases and sentences without mixing them with one's own words and statements in the papers or other research reports. Also, I should refer to the clarity in expressing and explaining everything to those who take part in your research because they have the right to know everything in detail and be aware of whatever is going to happen during the research process. They should also be made familiar with the objectives and aims of the study so that they would be more collaborative and have sufficient motivation for collaborating with the researcher. The order of appearance of the researchers' names on a research manuscript should be according to the role each of them had been playing in the accomplishment of the task. Otherwise, it would harm 
Zhila Gharaveisi,

Adel Dastgoshadeh

fairness and equity. I prefer to be an ethical researcher than an unethical one, but I really do not think every researcher has the same idea about adhering to ethical considerations in conducting research. The Iranians seem to be ethical people because of their religious orientations to things and to life. So, I guess many Iranian L2 researchers and even researchers from other fields of study adhere to ethics in research.

As can be seen in the preceding transcription, reference has been made to such ethical concerns as plagiarism, participant rights, and authorship rights. Of course, the respondent's tone in expressing the ethical considerations is a mild one which indicates an average sensitivity to adherence to these ethical issues while conducting research. Below, there is a more serious approach to ethical concerns and the extent to which they should be followed and adhered to by researchers.

We Iranians are extremely careful about not harming others and this is a motto in our religious sources. Despite the authority that university professors have over their students and despite the cultural habit of respecting teachers and professors, professors should strictly avoid exerting influence and power over their students by forcing them to place their professors' names before their own names although they have done the lion's share of the job. The next issue to be pointed out here is the importance of accurate and truthful representation of research data and the statistical analyses relating to the data. Manipulating even a small part of the data will render everything different and drastically change the direction of the findings. So, misrepresenting the data is a deadly act of unethicality. If the researcher tries to do so, why does $s /$ he conduct research at all? This is against ethical principles in research. It seems unlikely that the majority of researchers, at least as far as our own Iranian context is concerned, pay any attention to many of the ethical considerations and standards. But, I can assure you that I stick to ethical principles as far I can, though, frankly, there have been some occasions where I have failed to do so perfectly.

Explicitly stated in the preceding transcription are the ethical issues of authorship rights and data management. This participating teacher researcher was vividly concerned about university professors' misdeeds in maltreating their students by illegally and unethically forcing them into putting their professors' names as the primary author without claiming primary authorship for themselves who are usually the major contributors to a scientific work, be it published research papers or other types of scholarly works such as books, etc. Also, this participant was clearly expressing concern about mismanagement of research data, whether in the form of data falsification or data fabrication. The former refers to the wrong representation and interpretation of research data, while the latter indicates instances of reporting data without actually having conducted any research and/or having collected any data. Further transcriptions of the participants' responses are presented below.

Many researchers take much of participants' time by requiring them to answer lengthy questionnaires or attend long hours or even many sessions of experimental treatment without informing them what all these are good for. Sometimes, this unwarranted participation can be at the expense of the subjects' own educational goals and routine work because they are detached from their usual classroom settings and deprived of their normal instruction to save time for the research experiments and treatments. The poor subjects do not even know what is going on and why they are being engaged in the research project. Actually, this is not ethically 
warranted. Complete justification for their participation in the research along with the benefits and goals of the research being conducted should be explained to the participants. Equally important is the issue of data faking and data falsification which should strictly be avoided even though no pattern of results would be obtained. I try my best to follow such ethical considerations whenever I carry out research. This is because I consider these pieces of knowledge no less important than a researcher's technical knowledge and professional research qualification. As for other researchers in the field, I think few people apply ethical principles to their research, which I regret a lot.

The above transcription emphasizes the research participant's rights and data management. The participant's self-expressed adherence to research ethics seems to go hand in hand with the extent to which s/he values and prioritizes ethical considerations. In other words, in the majority of cases, those researchers who are concerned about ethical issues in conducting research seem to be adhering to such issues, while those who do not take ethical considerations seriously do not show any commitment to applying ethical principles to their research studies and do not even recommend other researchers inside the country to care about ethical matters in research. A final instance of participants' perspectives on research ethics will be presented below with the hope of providing an exhaustive sample of the results.

I believe plagiarism is a critical ethical consideration to be dealt with and taken seriously by researchers and other scholars in the field of SLA research. Violations of ethical citation will demotivate many writers because they observe their authorship rights ruined by other novice or unprofessional writers and/or researchers. I strongly condemn plagiarism as a severe case of academic misconduct. It includes not only unlawful use of other people's words as one's own but also their ideas as well as the unacknowledged paraphrasing of their words and/or ideas. I think there exists an even more severe case of plagiarism whereby an author illegally becomes the number one author and claims primary responsibility for a work even though this is not really the case.

The above quote emphasizes plagiarism and authorship rights as two important instances of ethical considerations in conducting research. It foretells or highlights the significance of crediting other researchers' beliefs, statements, and empirical findings so as to guarantee both their authorship rights and the validity of the subsequent claims based on them.

Some peripheral instances of ethical considerations, which were sporadically mentioned by some participants but failed to become emerging themes, will be presented below.

A researcher must try his best to acknowledge any possible misconduct and whatever shortcoming, limitation and delimitation which are likely to negatively affect the research results.

An ethical issue relates to researchers' bonesty in submitting a manuscript only to one journal to be considered for publication. But, unfortunately some researchers simultaneously submit a work to more than one journal, which is sometimes a waste of time and energy put into the job for reviewing. 
Zhila Gharaveisi,

Adel Dastgoshadeh

The nonstandard review criteria and sometimes contradictory comments by the same reviewer across resubmission or by different reviewers across different journals should be prevented.

These miscellaneous views address different positions about research ethics which are not necessarily covered under the four emerging themes, but each one relates to a subsidiary ethical priority. Their views do not directly tap into the four emerging themes, but they also relate to the general principles of research ethics and can generally be considered as belonging to ethical considerations in doing research.

\section{Discussion}

This study explores the perspectives and perceptions of Iranian English language teachers about ethical considerations in conducting SLA research. It centered around five questions about the definition, significance, instances, and adherence of ethical considerations of EFL teacher researchers in the Iranian context. Generally, a two-sided pattern of perspectives on research ethics came out of the participants' responses during the interviews. On the one hand are those teacher researchers who believed that ethics does not constitute an integral part of research and it need not be considered as a criterion for evaluating the quality of research studies. They were of the opinion that ethics is not important because it is not what the present society needs. Rather, it is the scientific contribution of a piece of research which is urgently needed by a society and its people. Such a conceptualization had probably prevented them from envisaging a clear definition of ethics in research studies. Their arguments against ethics centered upon the premise that ethics is not a technical and scientific component of research and does not contribute very much to the development of human knowledge in research studies. They imagined ethics as a trivial matter in the domain of scientific enquiry in which the aim is to add to world knowledge and solve scientific problems. In more precise terms, they conceived of ethics as a personal characteristic of human beings which has nothing to do with the realm of science. This seems, indeed, to be too positivistic an idea.

On the other hand, some researchers viewed awareness of research ethics as important as the technical knowledge of the underlying principles and premises of research methodology. They held the view that any research study which is not premised on sound ethical considerations cannot satisfy the requirements of scientific enquiry and fulfill its scientific functions. For them, ethics is interwoven into any aspect, step, and procedure of conducting research without which no part of the study can be guaranteed in terms of truthfulness, objectivity, originality, genuineness, reliability, and usefulness. Such a view does not leave room for violating the principles of commitment, misrepresentation, and misconduct. Interestingly, the researchers in this latter group did have clear-cut definitions for research ethics and its significance in SLA research. This, in itself, reflects some degree of 
association between having a clear conceptualization of research ethics and being committed to it in practice.

Overall, four major themes came out of the researchers' perspectives and perceptions about ethical considerations in conducting research: namely, plagiarism, data management and representation, participant rights, and authorship rights. This finding, within the limits of this study, indicates that some of the L2 researchers in the Iranian context follow these four major themes of ethics in research. In other words, these appear to be the main ethical concerns to L2 researchers in Iran.

These four emergent themes were extracted from the responses of those researchers who showed more interest in and concern about ethical issues in research. Other researchers showed indifference towards which theme to take into account, parallel to their indifference towards proposing a definition of research ethics and elaborating on its role and significance. On the contrary, the other group of researchers exhibited much enthusiasm about the discussion of ethics out of which the four major themes emerged. The degree of importance attached to research ethics and its significance by each group of researchers was paralleled by an indication of their commitment and adherence to ethical matters in research.

The interested and committed group seemed to know in their responses what the concepts of plagiarism, data management, participant rights, and authorship rights mean. They also indicated their recognition and admittance of these concepts and acknowledged their significance in conducting research. Of course, not all of them equally highlighted and mentioned all four themes. Rather, each of them reflected on a number of the four major themes, which indicated that there was not a unanimous agreement about the significance of the four themes among all researchers in this group. Eventually, each of the researchers in this group referred to some of these themes while there was some degree of convergence among their perspectives so as to denote a general orientation. This shows that the four themes mentioned above constituted the major ethical concerns of the majority of the participants in the present study.

The findings of this study, both in terms of the four major themes and also the few additional ones, are in accord with a number of theoretical accounts of the ethical issues and also empirical studies on research ethics in the literature. For instance, they are in line with Aba-Sha'ar's $(2017$, p. 2) view that “... perception of ethics, its principles and its importance may significantly vary between individuals, disciplines, and countries". This view reflects the differences in opinion among the participants in this study. This study also agrees with the one by Mahdavi-Zafarghandi, et al. (2012) who found that Iranian masters students had an inadequate conceptualization of different forms of plagiarism. It also reflects Rezanejad and Rezaei's (2013) finding that students had different conceptualizations and perceptions of plagiarism, and plagiarism was mostly considered by them as the use of someone else's words 
Zhila Gharaveisi,

Adel Dastgoshadeh

as one's own, but they did not consider it to mean taking someone's ideas without permission. Furthermore, the four themes emerging in the present study show considerable overlap with the ones proposed in the publication manual by the American Psychological Association and Aba Sha'ar's (2017) list of codes of ethics. The view held by some researchers in this study in favor of the knowledge-producing function of research at the expense of ethics reminds one of the Iranian EFL teachers' commonly held beliefs that the aim of research is to produce new knowledge and address the practical problems of society (Mehrani, 2015).

Generally, the results suggest that L2 researchers in the Iranian context show an interest in and commitment to ethical codes and principles while conducting research. An additional point which is worth being considered is that the results of this study should be interpreted and generalized upon with caution, as it has been conducted on a relatively small sample of researchers and in only one geographical setting. Therefore, the representativeness of the sample and, consequently, the generalizability of the findings merit particular attention and caution.

\section{Conclusions and Suggestions}

Ethical considerations in research do not seem to be unanimously conceptualized and perceived by all researchers. Therefore, they do not have the same definition for every researcher in general, and the L2 researcher in particular. This is because different researchers have different perspectives on both research and ethical issues in conducting research. This difference in perspective may relate either to their views about the significance of ethical considerations or to their adherence to those considerations. For example, one characteristic of the teacher researchers participating in this study, which distinguished them in one respect, was their academic education degree. Interestingly, in the majority of cases, those researchers who had higher academic degrees held more positive and committed views about research ethics than those with lower academic degrees. The former group even declared higher levels of commitment and adherence to research ethics than the latter. Almost no pattern could be drawn vis-a-vis the responses of the latter group, as they did not think much of research ethics and were not willing to appear very committed to ethical principles because they conceived of ethics as a subsidiary aspect of research which need not concern a researcher too much.

Therefore, this study suggests that, unlike technical knowledge of research principles and methodology that are commonly considered as important throughout the world such as reliability, validity, and acceptability, ethical matters are not equally interpreted and followed by all researchers.

In sum, L2 researchers in the context of Iran, like those in any other context, do not appear to have the same perceptions of ethical issues in research. Furthermore, the extent to which they adhere to ethical considerations conceptually or while conducting research in 
practice differs across different researchers, at least in the SLA field, which is the focus of the present study. Due to such diversity in the views about research ethics, we cannot simply expect all research studies to be equally grounded in sound principles and, consequently, merit attention and positive evaluation, because any study violating ethical concerns and principles cannot be guaranteed in terms of other aspects of research principles and criteria.

The findings of this study have implications for those in charge of language teacher development programs in that they encourage and motivate them to incorporate ethical issues into their teacher training courses and programs. L2 researchers can also benefit from the findings of this study and come to recognize the significance of all aspects and dimensions of ethicality and ethical practice in conducting research. They should draw on the implications of such studies in realizing that all parties addressed by a research study, who in some way benefit from it, should be taken into consideration while conducting research, and this necessitates adhering to ethical principles of research.

Replications of this study with larger numbers of teacher researchers will be needed to provide more extensive explorations of the topic under investigation. This will increase the generalizability of the findings. The study can be replicated on teacher researchers from different parts of the Iranian context to see whether the results would be the same or different in terms of a wider coverage of areas instead of a specific geographical area of the country. The study can also be replicated quantitatively to provide statistical evidence for the results obtained.

\section{References}

Aba-Sha'ar, M. Y. (2017). Research ethics: A principal view. India: Aligarh Muslim University, U.P.

Ahmadi, A. (2012). Cheating on exams in the Iranian EFL context. Journal of Academic Ethics, 10(2), 151-170.

Allwright, D. (2005). Developing principles for practitioner research: The case of exploratory practice. The Modern Language Journal, 89(iii), 353-366.

Bamford, J., \& Sergiou, K. (2005). International students and plagiarism: an analysis of the reasons for plagiarism among international foundation students. Investigations in University Teaching and Learning, 2(2), 117-122.

Dörnyei, Z. (2007). Research methods in applied linguistics. New York: Oxford University Press.

Ellis, R. (1994). The study of second language acquisition. Oxford: Oxford University.

Gass, S., \& Selinker, L. (2007). Second language acquisition: An introductory course (3 ${ }^{\text {rd }}$ Ed.). Mahwah, NJ: Lawrence Erlbaum.

Gottlieb, A. (1997). Comments on ethical issues in qualitative research. Paper presented at the annual meeting of the American Educational Research Association, Chicago, USA. 
Hoepfl, M. (1997). Choosing qualitative research: A primer for technology education researchers. Journal of Technology Education, 9(1), 47-63.

Hoy, A. (2008). Commentary: What motivates teachers? Important work on a complex question. Learning and Instruction, 18, 492-498.

Hiver, P. H. (2010). The interplay of possible language teacher selves in professional development choices: $A$ qualitative study (Unpublished master's thesis). University of Nottingham, UK.

Kelman, H. C. (2007). Foreword. In A. J. Kimmel, Ethical issues in behavioral research: Basic and applied perspectives (pp. xii-xiv). Malden, MA: Blackwell.

Kimmel, A. J. (2007). Ethical issues in behavioral research: Basic and applied perspectives. Malden, MA: Blackwell.

Larsen-Freeman, D., \& Long, M. H. (1991). An introduction to second language acquisition research. London: Longman.

Mackey, A., \& Gass, S. (2005). Second language research: Methodology and design. New Jersey, US: Lawrence Erlbaum Associates (LEA).

Mahdavi-Zafarghandi, A., Khoshroo, F., \& Barkat, B. (2012). An investigation of Iranian EFL Masters students' perceptions of plagiarism. International Journal for Educational Integrity, 8(2), 69-85.

Mehrani, M. B. (2015). Iranian EFL teachers' conceptions of research: An explanatory mixed methods approach. RALs, 7(1), 95-117.

Newman, P., \& Ratliff, M. (2001). Introduction. In P. Newman \& M. Ratliff (Eds.), Linguistic fieldwork (pp. 1-14). Cambridge: Cambridge University Press.

Ortega, L. (2005). For what and for whom is our research? The ethical as transformative lens in instructed SLA. The Modern Language Journal, 89, 427-443.

Rezanejad, A., \& Rezaei, S. (2013). Academic dishonesty at universities: The case of plagiarism among Iranian language students. Journal of Academic Ethics, 11(4), 275-295. Springer Science and Business Media Dordrech.

Strauss, A., \& Corbin, J. (1990). Basics of qualitative research: Grounded theory procedures and techniques. Newbury Park, CA: Sage.

Seferoğlu, G., Korkmazgil, S., \& Ölçü, Z. (2009). Gaining insights into teachers' ways of thinking via metaphors. Educational Studies, 35(3), 323-335. 124 NJ: Lawrence Erlbaum.

VanPatten, B., \& Williams, J. (2007). Theories in second language acquisition: An introduction. Mahwah, 